\title{
Comparative Analysis of Dacryo Cysto-Rhinostomy: External Versus Endoscopic
}

\author{
Joumany Brahim Salem, Mehdi Khamaily, Imane Tarib, Sidi Dahi, Rachid Zarrouk, Yassine Mouzari, \\ Fouad El Asri, Karim Reda, and Abdelbarre Oubaaz
}

\section{ABSTRACT}

Dacryocystorhinostomy (DCR) is a surgical procedure that restores communication between the tear sac and the adjacent nasal cavity. Our work consists of a comparative study of the results of external dacryocystorhinostomy (EX-DCR) versus endoscopic endonasal dacryocystorhinostomy (EN-DCR), whose rate of therapeutic failure by endoscopic route estimated at $20 \%$ against only $7 \%$ in the case of external surgery.

Keywords: Dacryocystitis; Dacryocystorhinostomy; Endoscopic; External.

\section{INTRODUCTION}

Dacryocystorhinostomy (DCR) is a surgical procedure that restores communication between the tear sac and the adjacent nasal cavity. This definitive short-circuit of the lacrymonasal duct is obtained by removing the portion of bone and the mucous membrane interposed between these two natural cavities. External dacryocystorhinostomy has shown its long-term efficacy with a success rate of over $90 \%$. The endonasal approach to the tear ducts presents itself as a new physiological and aesthetic approach that is just as reliable as the external route and which now benefits from suitable instrumentation with an operating method as standardized as the external route. Our work consists of a comparative study of the results of dacryocystorhinostomy by external route versus by endonasal route.

\section{PATIENTS AND METHOD}

This is a retrospective study, comparing the repermeabilization of the lacrimal passages, by dacryocystorhinostomy external and endonasal routes, carried out on 78 patients, carried out between January and December 2019. This study was carried out by a team
Published Online: November 13, 2020

ISSN: 2593-8339

DOI: $10.24018 /$ ejmed.2020.2.6.523

Joumany Brahim Salem *

(e-mail: joumanybss@ ${ }^{@}$ gmail.com)

Mehdi Khamaily

Imane Tarib

Sidi Dahi

Rachid Zarrouk

Yassine Mouzari

Fouad El Asri

Karim Reda

Abdelbarre Oubaaz

All authors are with Department of Ophthalmology of the Mohammed V Military Teaching Hospital, Rabat, Morocco.

Faculty of Medicine and Pharmacy, Mohammed V University, Rabat, Morocco.

*Corresponding Author ophthalmology for the external route (38 patients) and ENT for the endo-nasal route (40 patients). Our studies only included obstructions acquired and sitting on the vertical tear ducts proved by probing of the latter.

\section{TECHNIQUES}

All DCRs were performed under general anesthesia with placement in the nasal cavity of a compress soaked in xylocaine 5\% naphazoline and a subcutaneous injection of xylocaine adrenaline at the operative site associated with controlled hypotension.

\section{A. External DCR Surgical Technique}

The external approach consisted of a linear incision inside the angular vein and in front of the internal canthus starting at the level of the canthal tendons, followed by a section of the anterior bundle of the internal palpebral tendon, with detachment of the lacrimal sac, wide osteotomy, intubation and placement of a bi-canalicular probe, opening of the lacrimal sac, opening of the nasal mucosa, suturing of the lacrimal -nasal mucous flaps into a single flap and closing of the skin plane. 


\section{B. Endoscopic Endonasal DCR Surgical Technique}

Endoscopic endonasal DCR was performed as follows: incision at the level of the lateral nasal wall, anterior superior to the insertion of the median turbinate with lifting of the posterior mucosal flap of the jawbone followed by an incision until the bag is exposed. Metal tear catheters are passed medially through the two canaliculi so as to strain the lumen of the sac. A two-channel silicone tube is then positioned and tied. Postoperative care consisted of topical antibiotic corticosteroid treatment for two weeks, washing of the nasal cavities with physiological saline for four weeks and systemic antibiotic therapy to cover the nasal wicking. The postoperative follow-up took an average of 8 months.

\section{RESULTS}

Our series included 78 patients, 32 men (41.02\%) and 46 women $(58.97 \%)$. The average age of our patients is 42 years for men and 45 years for women; with extremes ranging from 22 to 70 for men and 28 to 76 for women. The involvement was unilateral in 63 cases $(80.76 \%)$. A history of cranio-facial trauma is found in $6.41 \%$ of patients, $76.93 \%$ of our patients have already presented with acute dacryocystitis, $5.12 \%$ orbital cellulitis, $10.25 \%$ a history of DCR in the other eye, $10.25 \%$ hypertension, and $7.69 \%$ diabetes. The ophthalmologic signs presented are a clear lacrimation isolated in $35.78 \%$, purulent in $64.22 \%$, a painless and depressible soft internal canthal swelling indicating a dacryocele in $9.17 \%$, a mucopurulent reflux through the lacrimal points to the pressure of the sac region in $33 \%$ of cases. (Fig. 1) (Fig. 2 A, B). When checking the patency of the tear ducts all patients have bone contact present. All the patients underwent an examination of the facial mass and a rhinological examination with a flexible naso-fibroscope in order to study the operative site and the nasal cavity in search of an associated rhino sinus pathology. A mucous bridge between the middle turbinate and the septal septum is found in $2.56 \%$ of patients already operated externally. A polypoid degeneration of the mucous membrane of the middle meatus is found in $1.28 \%$. Hypertrophy of the inferior turbinates is found in $2.56 \%$, a significant septal deviation is found in $6.41 \%$ of patients. (Fig. 3).

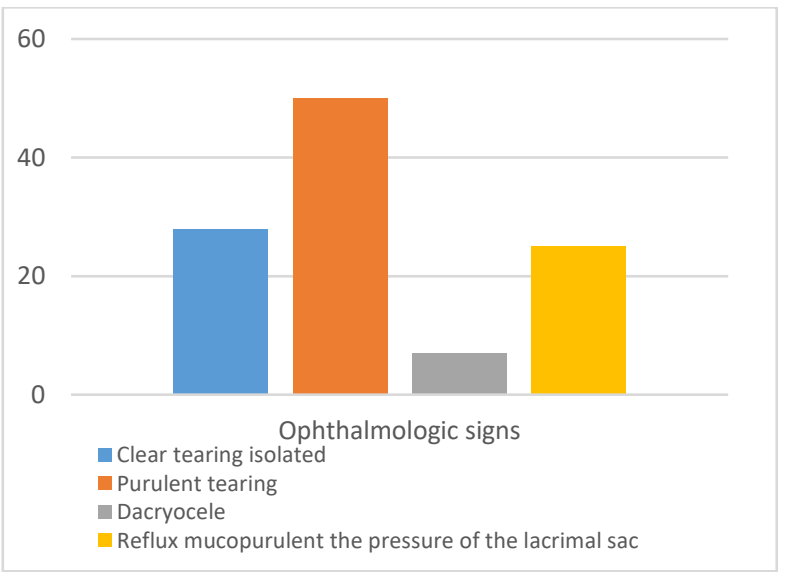

Fig. 1 Ophthalmologic signs.
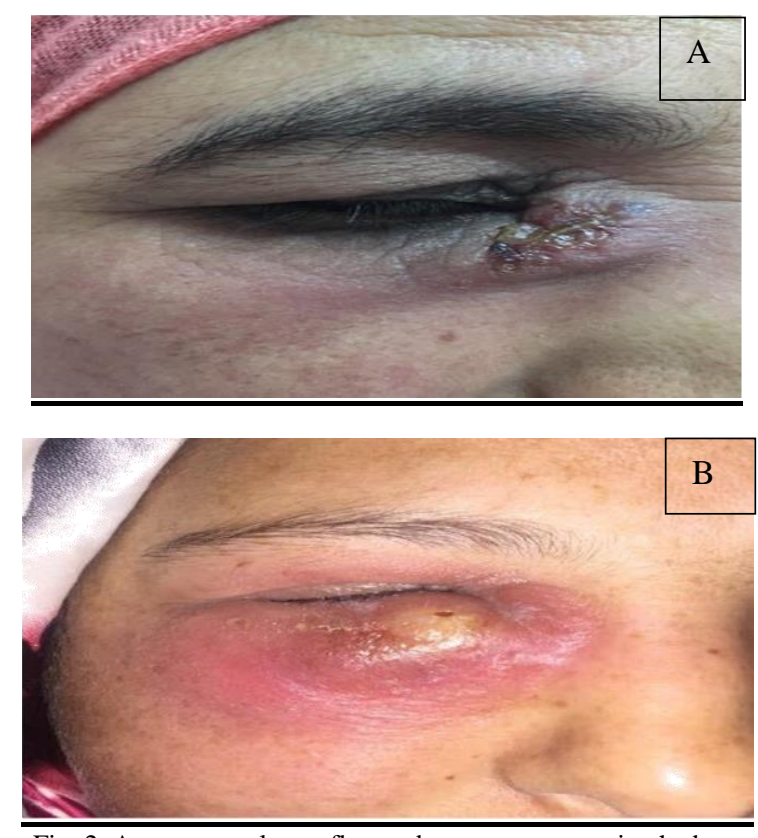

Fig. 2. A: mucopurulent reflux under pressure opposite the bag. $\mathrm{B}$ : dacryocele of the left eye with purulent lacrimation responsible for agglutination of the eyelashes.

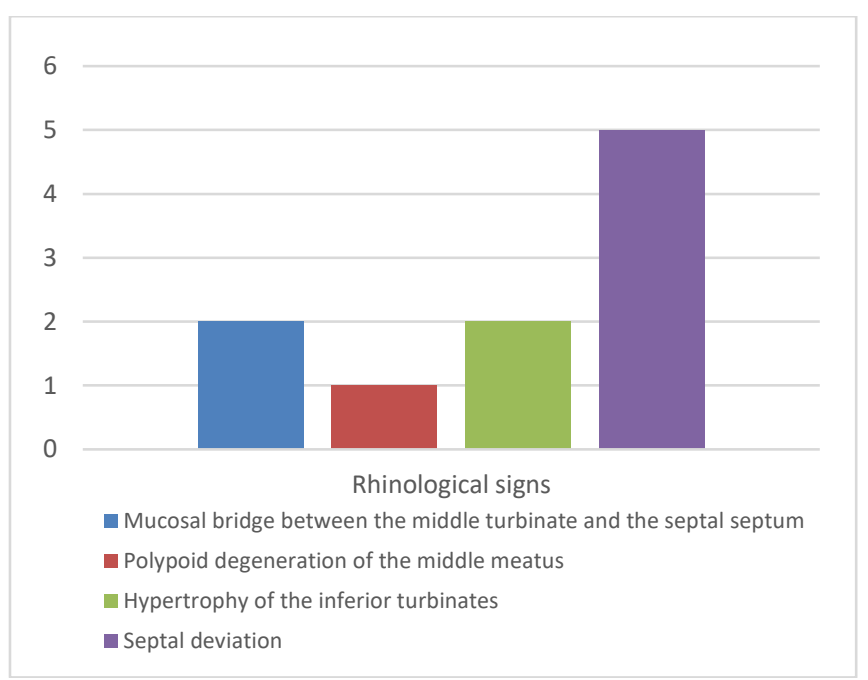

Fig. 3 Rhinological signs.

The surgical indications for the external approach and the endoscopic endonasal approach are presented in Table 1 and 2.

TABLE 1: DISTRIBUTION ACCORDING TO SURGICAL INDICATIONS FOR THE EXTERNAL ROUTE

\begin{tabular}{cc}
\hline Indication of external DCR & Number of cases \\
\hline chronic dacryocystitis & 30 \\
Chronic clear tearing & 3 \\
mucocele & 2 \\
revision surgery & 3 \\
\hline
\end{tabular}

TABLE 2: DISTRIBUTION ACCORDING TO SURGICAL INDICATIONS FOR THE ENDONASAL ROUTE

\begin{tabular}{cc}
\hline Indications de la voie endo-nasale & Number of cases \\
\hline Failure of DCR externally & 8 \\
Skin fistula & 2 \\
Dacryocele & 5 \\
$\begin{array}{c}\text { Rhino-sinus pathology with an } \\
\text { anatomical variant }\end{array}$ & 15 \\
Aesthetic goal or refusal of the \\
external route
\end{tabular}


The CT scan was performed in 8 cases of external DCR failure with identification of the site of the obstacle at the sac and lacrimal-nasal duct junction in the majority of cases. In patients operated externally, intraoperative hemorrhage was observed in $28.2 \%$ of our patients, tears of the nasal mucosa were found in $31.58 \%$ and tears of the lacrimal sac in $18.42 \%$. The bichannel catheter is placed in 78 operations ( $100 \%$ of cases) with a lead time of withdrawal of the lead which varies between 2 and 6 months with an average delay of 3 months. Withdrawal of the bichannel catheter in revisions of external and endonasal DCR failures was later than 3 months. The degree of patient satisfaction with tearing was evaluated at one month postoperatively, after removal of the probe and at 6 months. The good results are the addition of patients with zero or reduced lacrimation with absence of recurrent episodes of acute dacryocystitis. Failures are cases of patients with persistent or unchanged lacrimation with recurrence of at least one episode of acute dacryocystitis. Thus, 41 patients have no lacrimation, 19 have a decrease in lacrimation and 18 have persistent lacrimation. The failure of endoscopic DCR in our series is $20 \%$ and the causes were an ethmoid bubble in 2 cases $(5 \%)$, an osteotomy that was too small in 4 cases $(10 \%)$, excessive fibrosis in 2 cases $(5 \%)$. The failure of external DCR is $7.89 \%$ and the cause was excessive fibrosis in 3 cases (Fig. 4).

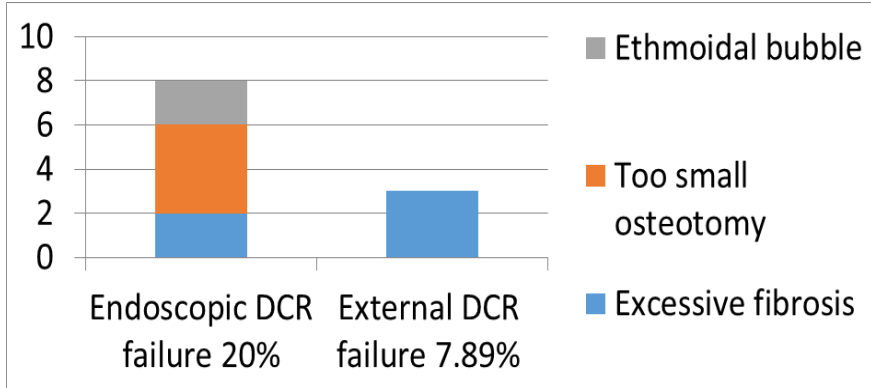

Fig. 4. Cause of therapeutic failure by the 2 surgical routes.

\section{DISCUSSION}

The incidence of dacryocystitis worldwide is estimated to be $0.02 \%$ [1]. In Spain [2], dacryocystitis constitutes $3 \%$ of consultations in ophthalmology departments, compared to $6 \%$ in Pakistan [3]. In our department, the incidence of dacryocystitis is $3.2 \%$ of all ophthalmologic pathologies. Dacryocystitis can appear at all ages of life, however it most commonly occurs in people in the sixth and seventh decades in developed countries, while it occurs in people 10 to 20 years younger in developing countries [3]-[5]. In our series, the average age is 44 years. Among adults, the majority of authors note the predominance of women in their studies [6]-[8] which is also the case in our series with a sex ratio of 0.69 . This female predominance is explained according to several authors by the fact that women have a narrow lacrymonasal duct [9].

All of our patients present with lacrimation, which in most cases constitutes the reason for consultation with the service, of which $35.78 \%$ of cases present purulent secretions. While only $17.5 \%$ of cases presented with swelling of the inner corner of the eye. This is consistent with the results of several studies such as that of Ducass A. et. al. [6] reporting lacrimation in $82.2 \%$, purulent secretions in $17 \%$ and swelling of the internal angle of the eye in $0.8 \%$.In our series, all the patients presented impermeable tear ducts, which is consistent with the results of several studies such as those of Mohamed Salahuddin Ahmed et al where the tear ducts were impermeable with $50 \%$ complete blockage and 50\% incomplete [10]. A study conducted Mohamed Salahuddin Ahmed et al had noted the presence of some known nasal abnormalities pre-disposing of an obstruction of the lacrymonasal duct such as deviation of the nasal septum found in $90 \%$ of cases, hypertrophy of the nasal turbinate found in $15 \%$ of cases, sinusitis in 5\% [10]. The traumatic cause is the most frequent cause of specific strictures in several series, while in ours it is rather sarcoidosis that predominates the specific strictures [11][13]. External DCR had been the major choice of surgery for years, but an unsightly skin scar on the incision, the risk of damage to the medial canthal structures, impaired function of the tear pump mechanism and even cerebrospinal fluid rhinorrhea are some of the hazardous complications of this surgery [14], [15]. Endonasal DCR has many advantages, including the conservation of the physiology of the tear pump mechanism, the absence of visible scars, the shorter operative time and an earlier postoperative recovery time [13], [14], [16]. The anatomical success rate in our series of external DCR was $92.11 \%$ versus $80 \%$ for endoscopic DCR these rates are comparable to the rate found in several studies [14], [17]-[20]. By the two types of (DCR), some serious complications such as orbital and subcutaneous emphysema, retrobulbar hemorrhage, medial paresis and orbital hernia are reported in the literature [21]-[23]. We did not observe any serious complications in our study. Intraoperative bleeding was the most common complication and was reported in $48 \%$ of cases in external DCR and $4 \%$ in endonasal DCR which was significantly different in the two surgeries. Rose et al [24] defined a divergence on the results of subjective and objective success of DCR operations, suggesting that anatomical success may not be correlated with success in symptom control and vice versa. Relief of discharge-related symptoms may not be possible in all patients, especially if there is hydraulic resistance of the canaliculi and nasolacrimal ducts [14], [24]. Although all the patients in our study had a patent tear lavage and a positive Functional Endoscopic Dye Test (FEDT) at the end of the first postoperative month; one patient in the external DCR group reported a low grade of epiphora, even after one year. This can be explained by the tear pump mechanism disturbed by the external approach [25], [26]. In a study by Feretis et al [27] based on the GBI scale with an additional symptomatic questionnaire, by department distributed to all patients. The results indicated positive scores for both groups, with no statistically significant difference between the results of the external and endonasal procedures. The results of the ocular symptomatology questionnaire indicated better scores for the outpatient procedure, but this difference was not statistically significant. External DCR provided greater improvement in quality of life, but the difference between groups did not reach statistical significance. Ho et al [28] conducted a prospective nonrandomized series evaluating the impact of endonasal surgical DCR on quality of life. The GBI scores reported in 
this study appear to confirm previous findings that external surgical and endonasal DCR produced a positive postinterventional change in patient health status, but the difference between the groups was negligible [29].

\section{CONCLUSION}

Chronic dacryocystitis is an obstruction of the lacrimal duct in connection with an inflammation of the lining of the lacrimal sac. Dacryocystorhinostomy is the surgical treatment for chronic dacryocystitis, it re-waterproofs the tear ducts to suppress tearing and avoid long-term complications. Its two pathways, external and endonasal, are opposed anatomically but not therapeutically. Endonasal DCR has been brought up to date thanks to new operating methods, which are endoscopy and laser, but it requires cooperation between otolaryngologists and ophthalmologists on the one hand, and expensive equipment on the other.

\section{REFERENCES}

[1] Woog J. J. The incidence of symptomatic acquired lacrimal outflow obstruction among residents of Olmsted County, Minnesota, 19762000 (an American Ophthalmological Society thesis). Trans Am Ophthalmol Soc. 2007; 105: 649-66.

[2] Balloon Catheter Dilation and Nasolacrimal Intubation for Treatment of Nasolacrimal Duct Obstruction Following a Failed Probing. Arch Ophthalmol. mai 2009; 127(5): 633-9.

[3] 36-13.pdf [Internet]. [cité 18 oct 2020]. Disponible sur: http://scolarite.fmp-usmba.ac.ma/cdim/mediatheque/e_theses/3613.pdf.

[4] Irfan D. To compare the success rate of External Dacryocystorhinostomy with and without Silicon Intubation in patients of nasolacrimal duct obstruction: 3 .

[5] Sadiq SA, Ohrlich S, Jones NS, Downes RN. Endonasal laser dacryocystorhinostomy--medium term results. $\mathrm{Br} J$ Ophthalmol. déc 1997; 81(12): 1089-92.

[6] www.unitheque.com. Les voies lacrymales [Internet]. Unithèque. [cité 18 oct 2020]. Disponible sur: https://www.unitheque.com/les-voieslacrymales/sfo/elsevier-masson/Livre/6243.

[7] Boboridis KG, Bunce C, Rose GE. Outcome of external dacryocystorhinostomy combined with membranectomy of a distal canalicular obstruction. Am J Ophthalmol. juin 2005; 139(6): 1051-5.

[8] Janssen A. G., Mansour K., Bos J. J., Manoliu R. A., Castelijns J. A. Abscess of the Lacrimal Sac due to Chronic or Subacute Dacryocystitis: Treatment with Temporary Stent Placement in the Nasolacrimal Duct. Radiology. 1 avr 2000; 215(1): 300-4.

[9] Winther J. Dacryocystorhinostomy A.M. Iliff A Long-Term FollowUp. Acta Ophthalmol (Copenh). 1982; 60(4): 564-7.

[10] Ahmed DMS. A Clinical Study of Chronic Dacryocystitis:105.

[11] Khan M. K. H., Hossain M. A., Hossain M. J., Al-Masud A., Rahman M. Z. Comparative Study of External and Endoscopic Endonasal Dacryocystorhinostomy for the Treatment of Chronic Dacryocystitis. J Armed Forces Med Coll Bangladesh. 2011; 7(2): 15-7.

[12] Durvasula V. S. P., Gatland D. J. Endoscopic dacrocystorhinostomy: long-term results and evolution of surgical technique. J Laryngol Otol. août 2004; 118(8): 628-32.

[13] Karim R., Ghabrial R., Lynch T., Tang B. A comparison of external and endoscopic endonasal dacryocystorhinostomy for acquired nasolacrimal duct obstruction. Clin Ophthalmol Auckl NZ. 2011; 5: 979-89.

[14] Tarbet K. J., Custer P. L. External dacryocystorhinostomy. Surgical success, patient satisfaction, and economic cost. Ophthalmology. juill 1995; 102(7): 1065-70.

[15] Gauba V. External versus endonasal dacryocystorhinostomy in a specialized lacrimal surgery center. Saudi J Ophthalmol Off J Saudi Ophthalmol Soc. janv 2014; 28(1): 36-9.

[16] Hamilton W. J., Mossman H. W., Boyd J. D. Hamilton, Boyd and Mossman's human embryology: prenatal development of form and function. London; Basingstoke; [Baltimore: Macmillan Press ; Williams and Wilkins; 1978.

[17] Ben Simon G. J., Joseph J., Lee S., Schwarcz R. M., McCann J. D., Goldberg R. A. External versus endoscopic dacryocystorhinostomy for acquired nasolacrimal duct obstruction in a tertiary referral center. Ophthalmology. août 2005;112(8):1463-8.

[18] Su P.-Y. Comparison of endoscopic and external dacryocystorhinostomy for treatment of primary acquired nasolacrimal duct obstruction. Taiwan $J$ Ophthalmol. mars 2018;8(1):19-23.

[19] Ozer S., Ozer P. A. Endoscopic vs external dacryocystorhinostomycomparison from the patients' aspect. Int J Ophthalmol. 18 août 2014;7(4):689-96.

[20] Huang Y.-M., Huang Y.-Y., Yang H.-Y., Tsai C-.C., Yu W.-K., Kao S.-C., et al. Conjunctival papilloma: Clinical features, outcome, and factors related to recurrence. Taiwan J Ophthalmol. 2018;8(1):15-8.

[21] Dave T. V., Mohammed F. A., Ali M. J., Naik M. N. Etiologic analysis of 100 anatomically failed dacryocystorhinostomies. Clin Ophthalmol Auckl NZ. 28 juill 2016; 10: 1419-22.

[22] Altin Ekin M., Karadeniz Ugurlu S., Aytogan H., Sahin Atik S. Failure in Revision Dacryocystorhinostomy: A Study of Surgical Technique and Etiology. J Craniofac Surg. févr 2020;31(1):193-6.

[23] Zhou W., Zhou M., Li Z., Wang T. Endoscopic Intranasal dacryocystorhinostomy in forty-five patients. Chin Med J (Engl). oct 1996;109(10):747-8.

[24] Saha R., Sinha A., Phukan J. P. Endoscopic versus external approach dacryocystorhinostomy: A comparative analysis. Niger Med J J Niger Med Assoc. 2013; 54(3): 165-9.

[25] Rizvi S. A. R., Saquib M., Maheshwari R., Gupta Y., Iqbal Z., Maheshwari P. Cosmetic evaluation of surgical scars after external dacryocystorhinostomy. Int J Ophthalmol. 18 déc 2016; 9(12): $1745-50$.

[26] Lin G. C., Brook C. D., Hatton M. P., Metson R. Causes of dacryocystorhinostomy failure: External versus endoscopic approach. Am J Rhinol Allergy. 1 mai 2017; 31(3): 181-5.

[27] Moras K., Bhat M. External Dacryocystorhinostomy Versus Endoscopic Dacryocystorhinostomy: A Comparison. J Clin Diagn Res. 2011; 5:5.

[28] Ho A., Sachidananda R., Carrie S., Neoh C. Quality of life assessment after non-laser endonasal dacryocystorhinostomy. Clin Otolaryngol Off J ENT-UK Off J Neth Soc Oto-Rhino-Laryngol Cervico-Facial Surg. oct 2006; 31(5): 399-403.

[29] Vinciguerra A, Nonis A, Resti AG, Bussi M, Trimarchi M. Impact of Post-Surgical Therapies on Endoscopic and External Dacryocystorhinostomy: Systematic Review and Meta-Analysis. Am J Rhinol Allergy. nov 2020; 34(6): 846-56. 